\title{
Intratumoral depletion of regulatory T cells using CD25-targeted photodynamic therapy in a mouse melanoma model induces anti- tumoral immune responses
}

\author{
Dong Sun Oh ${ }^{1, *}$, Heegon Kim ${ }^{3,4, *}$, Ji Eun Oh${ }^{2}$, Hi Eun Jung ${ }^{1}$, Yun Soo Lee ${ }^{3,4}$, Ji-Ho \\ Park $^{3,4}$ and Heung Kyu Lee L,2,4 $^{1,4}$ \\ ${ }^{1}$ Biomedical Science and Engineering Interdisciplinary Program, Korea Advanced Institute of Science and Technology, KAIST, \\ Daejeon, 34141, Republic of Korea \\ ${ }^{2}$ Graduate School of Medical Science and Engineering, KAIST, Daejeon, 34141, Republic of Korea \\ ${ }^{3}$ Department of Bio and Brain Engineering, KAIST, Daejeon, 34141, Republic of Korea \\ ${ }^{4}$ KAIST Institute for Health Science and Technology, KAIST, Daejeon, 34141, Republic of Korea \\ *These authors contributed equally to this work \\ Correspondence to: Ji-Ho Park, email: jihopark@kaist.ac.kr \\ Heung Kyu Lee, email: heungkyu.lee@kaist.ac.kr \\ Keywords: photodynamic therapy, immunotherapy, Treg, CD25, Chlorin e6
}

Received: January 06, 2017 Accepted: April 21, 2017 Published: May 07, 2017

Copyright: Oh et al. This is an open-access article distributed under the terms of the Creative Commons Attribution License 3.0 (CC BY 3.0 ), which permits unrestricted use, distribution, and reproduction in any medium, provided the original author and source are credited.

\section{ABSTRACT}

Tumor immunotherapy aims to overcome the immunosuppressive microenvironment within tumors, and various approaches have been developed. Tumor-associated $\mathbf{T}$ regulatory cells (Tregs) suppress the activation and expansion of tumor antigenspecific effector $\mathbf{T}$ cells, thus, providing a permissive environment for tumor growth. Therefore, optimal strategies need to be established to deplete tumor-infiltrated Tregs because systemic depletion of Tregs can result in reduced anti-tumor effector cells and autoimmunity. Here, to selectively deplete Tregs in tumors, we intratumorally injected anti-CD25 antibodies conjugated to Chlorin e6 (Ce6), a photosensitizer that absorbs light to generate reactive oxygen species. Local depletion of tumor-associated Tregs with photodynamic therapy (PDT) inhibited tumor growth, which was likely due to the altered tumor immune microenvironment that was characterized by increased infiltration of CD8+ effector T cells and the expression of IFN-Y and CD107a, which is a cytolytic granule exocytosis marker in tumor tissues. Furthermore, PDT-induced intratumoral Treg depletion did not influence adaptive immune responses in a murine influenza infection model. Thus, our results show that intratumoral Treg-targeted PDT could specifically modulate tumor microenvironments by depleting Tregs and could be used as a novel cancer immunotherapy technique.

\section{INTRODUCTION}

Tumor immunotherapy using antibodies, tumor vaccines, and cell-based therapies has been developed to eliminate tumors and to suppress tumor metastasis [1-3]. These tumor immunotherapies result in fewer side effects and are less invasive than conventional tumor therapies [4]. Recent advances in immunotherapies targeting immune-checkpoint molecules or immunosuppressive cells, such as regulatory $\mathrm{T}$ cells (Tregs) or myeloidderived suppressor cells, have been highlighted in tumor treatments [5]. Tregs are considered one of the most significant targets as they play a major role in maintaining immunosuppressive microenvironments within tumors $[6,7]$.

Though many advances have been made, there are several issues that must be overcome to achieve successful tumor immunotherapies [8-10]. Most importantly, systemic depletion of Tregs has the potential to induce severe autoimmune diseases and hyper-immune responses against other pathogenic infections. Therefore, successful immunotherapy requires specific local and selective 
depletion of Tregs to avoid these side effects and to protect homeostasis in other organs [11].

Photodynamic therapy (PDT) exploits non-toxic photosensitizers that absorb light to generate reactive oxygen species (ROS) that can kill tumor cells by inducing apoptosis or necrosis [12,13]. Light-dependent activation of photosensitizers enables site-specific treatment of tumors and helps reduce systemic toxicity compared to conventional chemotherapies $[14,15]$. In addition, conjugation of photosensitizers to targeting agents, such as antibodies, could provide cell-specificity and/or sitespecificity, further reducing off-target effects $[16,17]$. Similarly, antibodies targeting immune cells could be exploited for selective depletion of target cells in tumor microenvironments to investigate their functions and therapeutic effects [18].

Here, we intratumorally injected Chlorin e6 (Ce6) conjugated to an anti-CD25 monoclonal antibody (antiCD25-Ce6) to locally deplete $\mathrm{CD}^{+}{ }^{+} \mathrm{Foxp}^{+}$Tregs. This anti-CD25-Ce6-targeted PDT technique induced apoptosis and depletion of Tregs in tumors and inhibited tumor growth in a murine melanoma model. These effects are attributed to the altered immune microenvironment of the tumors, which was characterized by increased infiltration of $\mathrm{CD}^{+}$effector T cells and increased IFN- $\gamma$ and CD107a production in tumor tissues. Furthermore, local depletion of Tregs via PDT did not influence adaptive immune responses against flu infection, suggesting that anti-CD25Ce6-targeted PDT induced anti-tumoral immunity without altering systemic immune responses.

\section{RESULTS}

\section{Anti-CD25-Ce6-targeted PDT induces apoptosis in $\mathrm{CD}^{+} \mathrm{Foxp3}^{+}$cells in vitro}

Our first aim was to eliminate intratumoral Tregs by employing anti-CD25 antibody conjugated to $\mathrm{Ce} 6$ (antiCD25-Ce6; Figure 1A). CD25 is a significant marker for Tregs and has, thus, been widely used for depletion of Tregs [19-22]. Ce6 is a photosensitizer that can generate ROS or heat when excited under irradiation by a $660-\mathrm{nm}$ laser; the ROS generated can induce apoptosis in cells $[23,24]$. For the conjugation of $\mathrm{Ce} 6$ to anti-mouse CD25 antibody, the carboxylic groups of $\mathrm{Ce} 6$ were linked to the antibody's amine groups using N-hydroxysuccinimide and 1-ethyl-3-(3-dimethylaminopropyl) carbodiimide. The number of $\mathrm{Ce} 6$ molecules conjugated to each antiCD25 antibody molecule was estimated by analyzing the absorbance data. Approximately $10 \mathrm{Ce} 6$ molecules were conjugated to each antibody molecule (Figure 1B). Protein gel electrophoresis showed that the molecular weight of anti-CD25-Ce6 was slightly increased compared with anti-CD25 antibody in terms of Ce6 attachment to the heavy and light chains of the CD25 antibody (Figure 1C).
To confirm that anti-CD25-Ce6 binds Tregs effectively, $\mathrm{CD}^{+} \mathrm{T}$ cells were sorted from spleen of Foxp3-GFP mice and stained with anti-CD25-Ce6, Ce6conjugated isotype-control antibody (isotype-Ce6), or dye-conjugated anti-CD25 monoclonal antibody (anti$\mathrm{CD} 25)$. Binding of each conjugate was detected with a fluorochrome-conjugated anti-rat $\operatorname{IgG}$ antibody. The anti-CD25-Ce6 conjugate bound $\mathrm{CD}^{+} \mathrm{Foxp}^{+}$cells at a comparable rate to anti-CD25, while the isotype-Ce6 did not (Figure 1D).

We next examined the selective phototoxicity of anti-CD25-Ce6 against $\mathrm{CD}^{+}{ }^{+} \mathrm{Foxp}^{+}$cells. $\mathrm{CD}^{+}{ }^{+} \mathrm{T}$ cells were sorted from spleens of Foxp3-GFP mice and treated with anti-CD25-Ce6 or isotype-Ce6. For PDT, a 660-nm laser was used to irradiate each well for $5 \mathrm{~min}$. Apoptosis was measured at $30 \mathrm{~min}$ and $15 \mathrm{~h}$ after irradiation by detecting annexin $\mathrm{V}$ expression using flow cytometry. At both time points, anti-CD25-Ce6 induced apoptosis in $\mathrm{CD}^{+}{ }^{+} \mathrm{Foxp}^{+}$cells more effectively than did isotypeCe6 (Figure 1E). Collectively, these results suggest that anti-CD25-Ce6 can selectively bind $\mathrm{CD} 4^{+} \mathrm{Foxp}^{+}$cells in tumors and induce apoptosis under irradiation.

\section{Anti-CD25-Ce6-targeted PDT induces $\mathrm{CD4}^{+} \mathrm{Foxp3}^{+}$Treg depletion and produces tumor regression in vivo}

Intravenous injection of anti-CD25 antibody for systemic depletion of Tregs results in autoimmune diseases [11]. To overcome this harmful side effect, we performed intratumoral injection of anti-CD25 antibody to locally and selectively deplete Tregs within the tumor microenvironment. To confirm binding of anti-CD25Ce6 to Tregs in vivo, anti-CD25-Ce6 was injected intratumorally in mice bearing B16-F10 melanoma. Tumors were collected $30 \mathrm{~min}$ after injection. Analysis of antibody binding revealed that intratumoral Tregs were effectively targeted by anti-CD25-Ce6 (Figure 2A).

To determine if tumor irradiation following injection of anti-CD25-Ce6 into tumors can selectively deplete intratumoral Tregs, we collected tumors following PDT (irradiation twice at a 2-day interval). Intratumoral Tregs were effectively reduced after irradiation (Figure 2B), while Tregs in the tumor-draining lymph node showed no significant changes (Figure 2C).

PDT effectively depleted tumor infiltrated $\mathrm{CD} 4^{+}$ $\mathrm{CD}_{25}{ }^{+}$Foxp3 $^{+}$Treg, as well as $\mathrm{CD}^{+}{ }^{+} \mathrm{CD} 25^{+}$Foxp3 $^{-} \mathrm{T}$ cells that exhibit pathologic features and have a potential to become Tregs $[25,26]$ (Supplementary Figure 1). Overall, our results show that local and selective depletion of $\mathrm{CD}^{+} \mathrm{CD} 25^{+} \mathrm{Foxp}^{+}$Tregs was achieved in vivo.

Next, we investigated whether intratumoral depletion of Tregs can inhibit tumor growth. We performed PDT on mice bearing B16-F10 melanoma (four times total at 2-day intervals). Measurement of tumor volumes revealed that the anti-CD25-Ce6-injected mice showed 
significant inhibition of tumor growth, while isotypeCe6 or free anti-CD25 showed no therapeutic effect (Figure 2D). Collectively, anti-CD25-Ce6 effectively bound and killed intratumoral Tregs in vivo and effectively inhibited tumor growth.

\section{Anti-CD25-Ce6-targeted PDT induces CD8 T-cell tumor infiltration}

In anti-tumor immune responses, $\mathrm{CD} 8^{+}$cytotoxic $\mathrm{T}$ cells are a key eradicator of tumor cells. Several studies
A

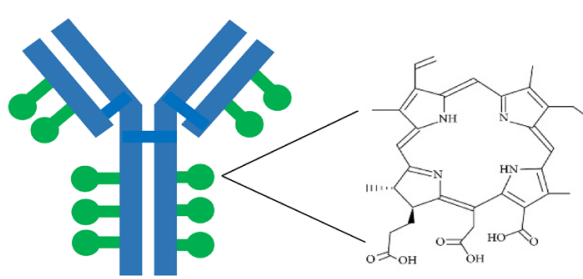

Anti-CD25 antibody Chlorin e6
B

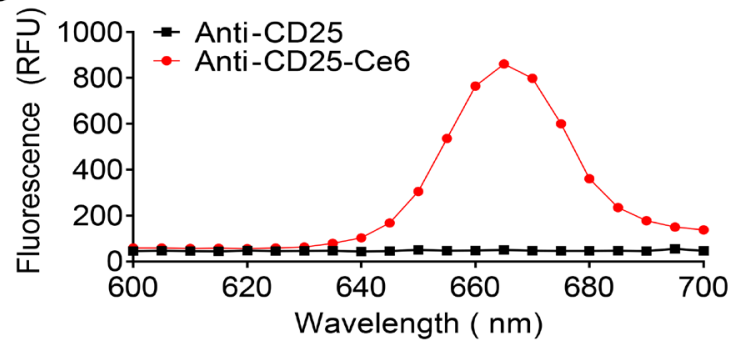

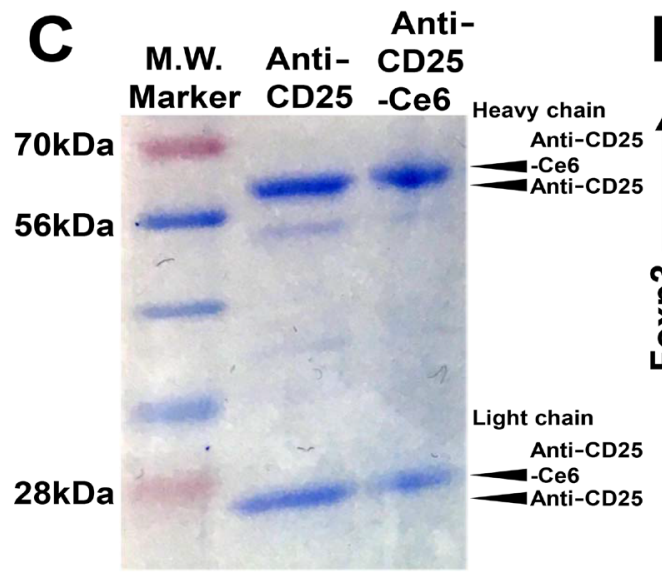

D

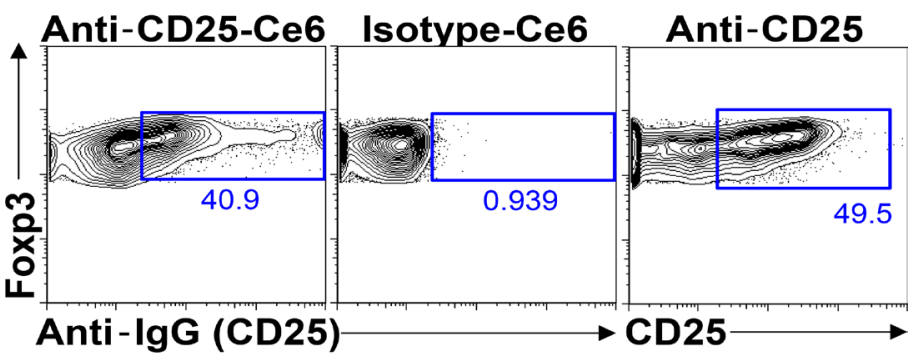

$\mathbf{E}$

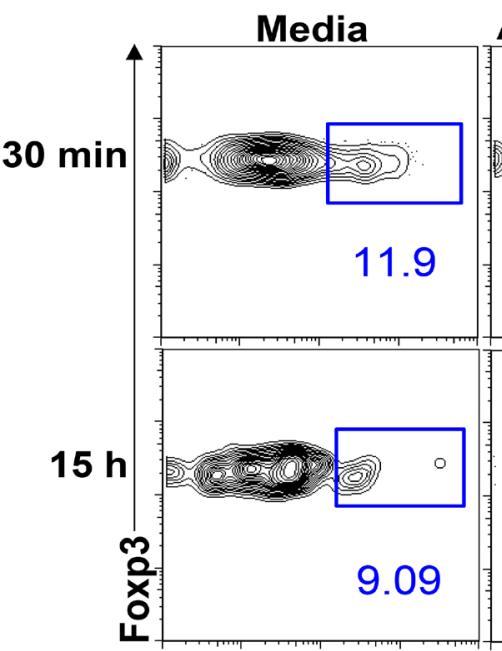

Anti-CD25-Ce6

Anti-CD25-Ce6 Isotype-Ce6 +

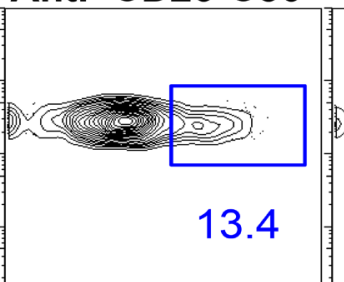
+ Irradiation Irradiation

Annexin V

Figure 1: Anti-CD25-Ce6-targeted PDT induces apoptosis of target cells in vitro. (A) Schematic of anti-CD25-Ce6 synthesization for treatment of mouse melanoma. Anti-CD25 antibody that can target Tregs are conjugated with Ce6 dye. (B) Fluorescence spectra of anti-CD25-Ce6 and anti-CD25 solutions with 400-nm excitation. (C) Anti-CD25-Ce6 and anti-CD25 was run on SDS-PAGE and stained with Coomassie blue dye. (D) $\mathrm{CD}^{+}{ }^{\mathrm{F}} \mathrm{Fxp} 3^{+}$cells were stained with anti-CD25-Ce6 or isotype-Ce6 conjugate, followed by APCconjugated goat anti rat secondary antibody. The binding efficiency of each conjugate was determined by flow cytometry. (E) $\mathrm{CD} 4^{+} \mathrm{Foxp} 3^{+}$ cells were irradiated with a 660 -nm laser. Cell apoptosis was observed at $30 \mathrm{~min}$ or $15 \mathrm{~h}$ after irradiation by detecting annexin V expression using flow cytometry. Data are representative of three or four independent experiments. 

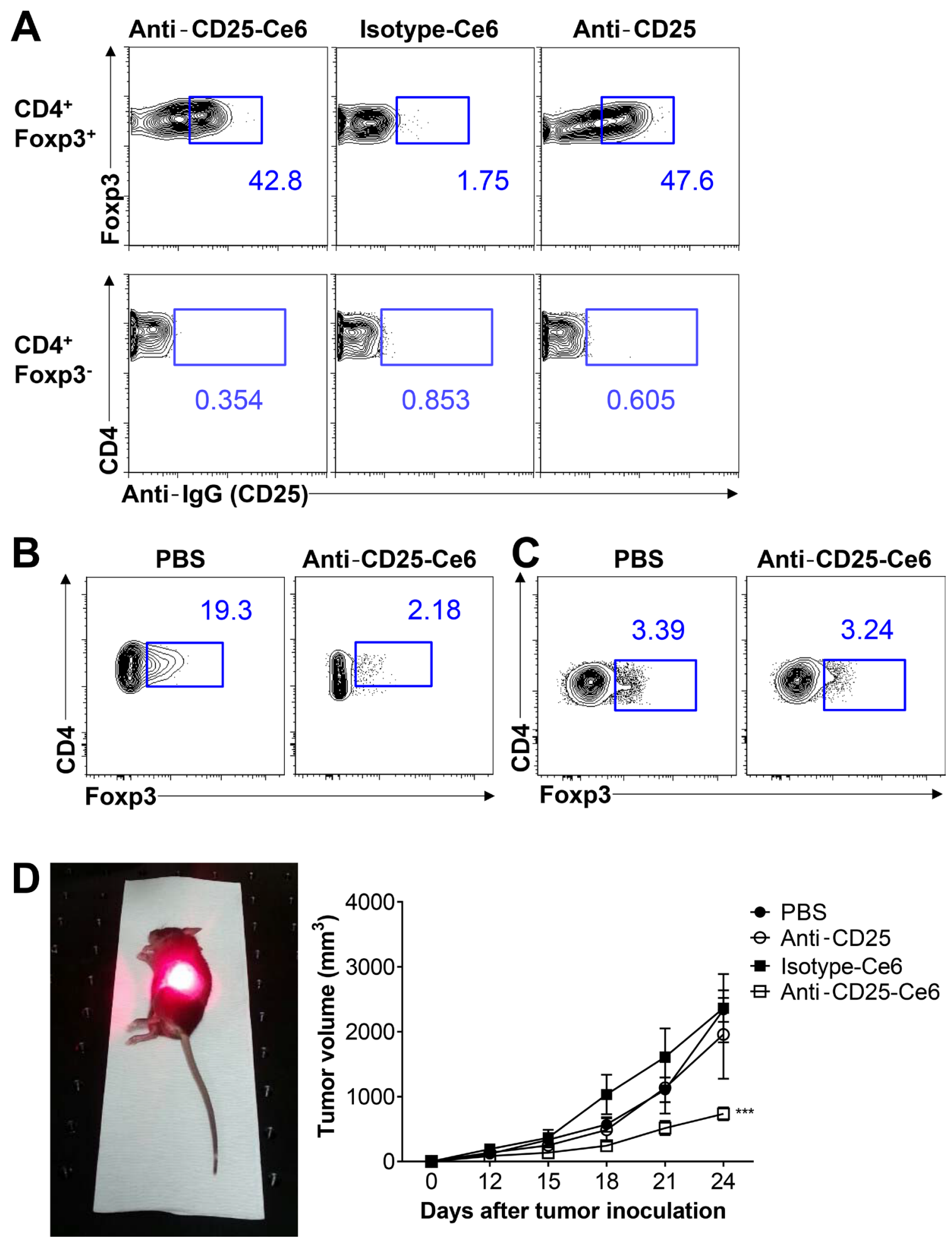

Figure 2: Anti-CD25-Ce6-targeted PDT induces depletion of intratumoral Tregs and regression of B16-F10 melanoma in vivo. (A) Anti-CD25-Ce6 or isotype-Ce6 conjugate was injected into B16-F10 tumor-bearing mice. After $30 \mathrm{~min}$, the binding efficiency of each complex was determined by flow cytometry following staining of fluorochrome-conjugated goat anti-rat IgG isotype-specific secondary antibody. (B and C) Ten days after B16-F10 melanoma cell transplantation, anti-CD25-Ce6 or PBS was injected intratumorally and tumors were irradiated with a 660 -nm laser for 20 min. Tumors were irradiated twice at a 2-day interval. B. Intratumoral or C. draining lymph node $\mathrm{CD}^{+} \mathrm{Foxp}^{+}$Tregs were monitored using flow cytometry. (D) PBS, anti-CD25 antibody, isotype-Ce6, or anti-CD25-Ce6 was injected intratumorally and PDT was conducted four times at 2-day intervals. Tumor growth was measured using a digital caliper. ( $n=5-6$ mice per group; two-way ANOVA, ${ }^{* * *} P<0.001$; error bars represent SEM). Data are representative of two or three independent experiments. 
have shown that Treg depletion induces activation of cytotoxic $\mathrm{CD}^{+} \mathrm{T}$ cells and enhances infiltration of these cells into tumors $[27,28]$. To determine if $\mathrm{CD}^{+}$cytotoxic T cells also infiltrate tumors after anti-CD25-Ce6-targeted PDT, we subcutaneously inoculated mice with B16-F10 melanoma cells. Ten days after tumor inoculation, PBS, isotype-Ce6, anti-CD25, and anti-CD25-Ce6 complex were injected intratumorally and tumors were irradiated with a $660-\mathrm{nm}$ laser for $20 \mathrm{~min}$. PDT was conducted twice at a two-day interval. Tumor-infiltrated $\mathrm{CD}^{+} \mathrm{T}$ cells and $\mathrm{CD}^{+} \mathrm{T}$ cells were monitored using flow cytometry. Tumor-infiltrated CD4 ${ }^{+}$T-cell levels were not significantly different between treatment groups. However, $\mathrm{CD}^{+} \mathrm{T}$-cell infiltration was elevated more in anti-CD25-Ce6-treated mice than in control (PBS, isotype-Ce6, and anti-CD25treated) mice (Figure $3 \mathrm{~A}$ and $3 \mathrm{~B}$ ). Thus, these results show that effective depletion of intratumoral Tregs through antiCD25-Ce6-targeted PDT enhances anti-tumor immunity by inducing $\mathrm{CD} 8^{+} \mathrm{T}$-cell infiltration.

\section{Anti-CD25-Ce6-targeted PDT induces cytotoxic T-cell responses and polyfunctionality}

Recent studies have demonstrated that tumorinfiltrated $\mathrm{CD}^{+} \mathrm{T}$ cells display several functional impairments, especially in their polyfunctional cytokine production that includes IFN- $\gamma$, TNF- $\alpha$, and CD107a, which are high-quality effectors [29]. Tregs contribute to the suppressed polyfunctionality of cytotoxic $\mathrm{CD}^{+}$ $\mathrm{T}$ cells [7]. Based on the hypothesis that local depletion of Tregs could recover the polyfunctionality of $\mathrm{CD}^{+} \mathrm{T}$ cells, we examined the functionality of tumor-infiltrated $\mathrm{CD}^{+} \mathrm{T}$ cells by measuring cytokine production. Ten days after tumor inoculation, anti-CD25-Ce6 was injected intratumorally and PDT was conducted twice at a 2-day interval. The anti-CD25-Ce6-treated mice showed the most significant increase in IFN- $\gamma$ production compared with anti-CD25- and isotype-Ce6-treated mice (Figure 4A). Similarly, the IFN- $\gamma^{+} \mathrm{CD} 107 \mathrm{a}^{+} \mathrm{CD}^{+}$polyfunctional cytotoxic T-cell population was significantly increased in the anti-CD25-Ce6-treated mice (Figure 4B). Thus, Treg depletion through anti-CD25-Ce6-targeted PDT increased IFN- $\gamma$ production by $\mathrm{CD}^{+} \mathrm{T}$ cells and enhanced their polyfunctionality.

\section{Anti-CD25-Ce6-targeted PDT does not affect the adaptive immune response against influenza infection}

Elimination of Tregs through systemic administration of monoclonal antibodies may reduce tumor masses by inducing anti-tumor immunity [22]. However, systemic Treg depletion results in severe side effects, such as autoimmune responses or hyper-immune responses against other pathogen infections [30, 31]. Therefore, these side effects are a major obstacle for clinical application of systemic Treg-targeting drugs. Our strategy that uses antibody-targeted PDT to locally and selectively deplete Tregs has the advantage of selectively targeting tumor-infiltrated Tregs, the most significant suppressor of anti-tumor immune responses in tumor microenvironments.

To verify that our therapy did not alter systemic immune responses, we utilized a mouse influenza infection model to determine if the influenza-specific immune response was altered following anti-CD25-Ce6-targeted PDT. Mice transplanted with B16-F10 melanoma were intranasally infected with PR8 virus. After two PDT treatments, PR8 NP ${ }_{366-374}$-specific $\mathrm{CD}^{+} \mathrm{T}$ cells in the lungs of each mouse were monitored by flow cytometry using $\mathrm{H} 2-\mathrm{Db}-\mathrm{NP}_{366-374}$ pentamers. The frequency and absolute cell number of influenza antigen-specific $\mathrm{CD}^{+} \mathrm{T}$ cells in the lungs of anti-CD25-Ce6-targeted PDT-treated mice were not significantly affected compared with the control groups (Figure 5A). In the case of intranasal PR8 infection after PDT treatment, there were no changes in the frequency or absolute cell number of influenza antigen-specific $\mathrm{CD}^{+} \mathrm{T}$ cells in the lungs (Supplementary Figure 2). Additionally, the humoral immune response against PR8 was also normal (Figure 5B). Together, these results suggest that our anti-CD25-Ce6-targeted PDT only modulated the tumor microenvironment through local depletion of Tregs, that resulted in tumor growth inhibition without affecting the adaptive immune response to influenza infection.

\section{DISCUSSION}

Many attempts to treat solid tumors by therapeutic vaccination have failed due to a poor understanding of tumor-induced immuno-suppressive microenvironments [32]. Tregs are essential for the regulation of autoimmune responses and induce tumor immune tolerance [33]. Therefore, Tregs are a promising target in the tumor microenvironment and the depletion of Tregs induces immune responses against tumors [34]. However, there are limitations to the current Treg depletion techniques in that systemic depletion of Tregs has the potential to induce severe autoimmune inflammation and hyper-immune responses against pathogen infections. Thus, an approach that locally and selectively depletes tumor-associated Tregs to avoid these severe side effects and protects the homeostasis of other organs is required.

Here, we used anti-CD25-Ce6-targeted PDT, in which the anti-CD25-Ce6 complex selectively binds to tumor-infiltrated $\mathrm{CD}^{+} \mathrm{Foxp}^{+}$Tregs and kill them locally in the tumor microenvironment by irradiation. The conjugation of $\mathrm{Ce} 6$ to anti-CD25 did not alter the binding activity of CD25 and effectively induced Treg apoptosis, affecting $60-70 \%$ of the Treg population $15 \mathrm{~h}$ after antiCD25-Ce6-targeted PDT. Tumor-infiltrated CD4 ${ }^{+}$Foxp $3^{+}$ Tregs highly express CD25, while CD4 ${ }^{+}$Foxp3- cells did 
not, allowing the anti-CD25-Ce6 complex to specifically target tumor-infiltrated Tregs. Therefore, local irradiation can be exploited to induce spatially selective depletion of $\mathrm{CD}^{+} \mathrm{CD} 25^{+}$Foxp3 $^{+}$Tregs. Recently, a similar approach was described that used photoactivatable silicaphthalocyanine dye (IRDye 700DX)-conjugated anti-Fab fragment of anti-CD25 to selectively deplete Tregs within MC38 murine colon adenocarcinoma and LL/2 Lewis lung carcinoma [18]. Here, we used the full form of an anti-CD25 antibody that can induce antibody-dependent cellular phagocytosis of $\mathrm{CD} 25^{+}$cells [22]. Even though tumor-infiltrated macrophages can induce antibody-
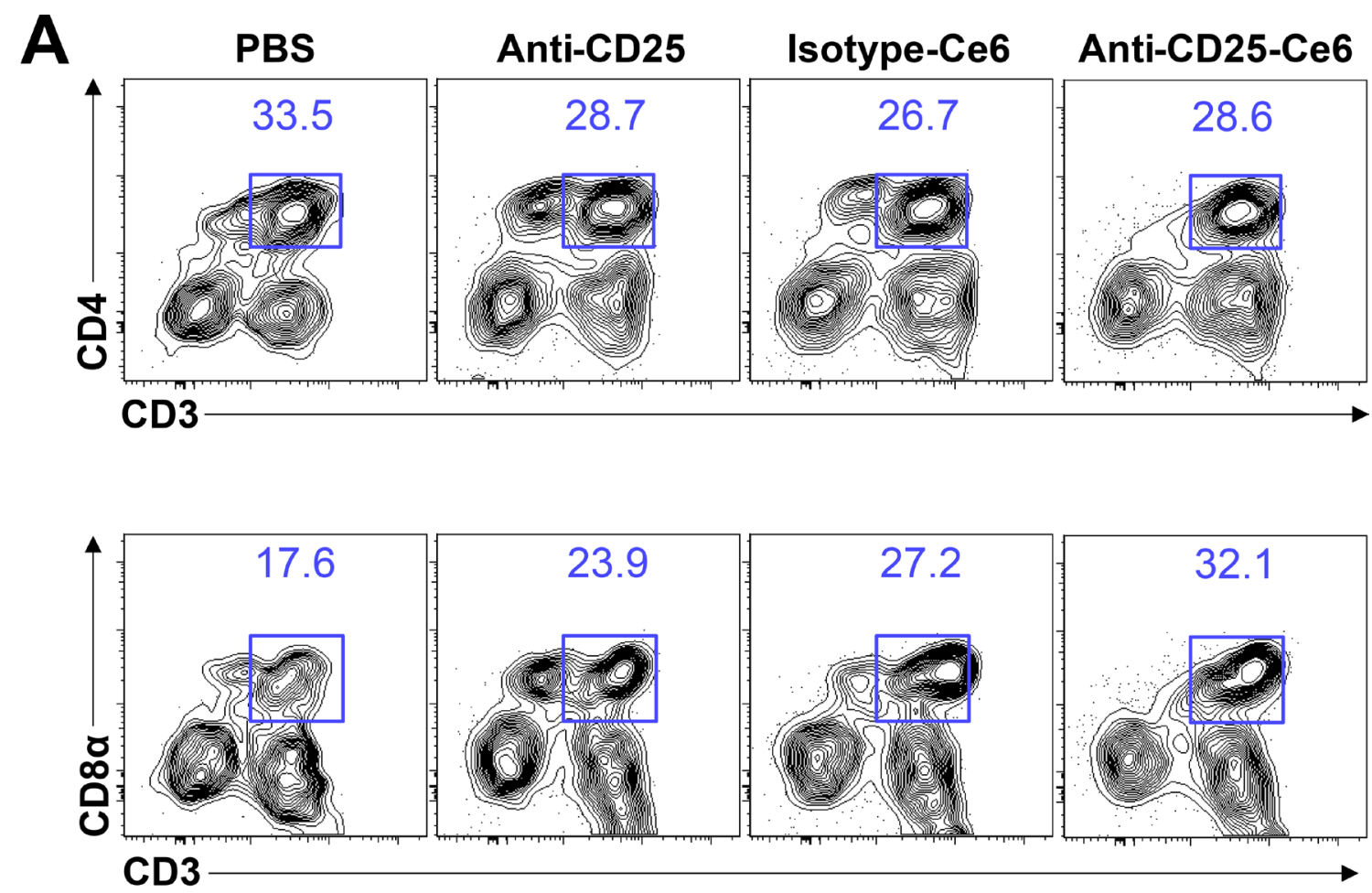
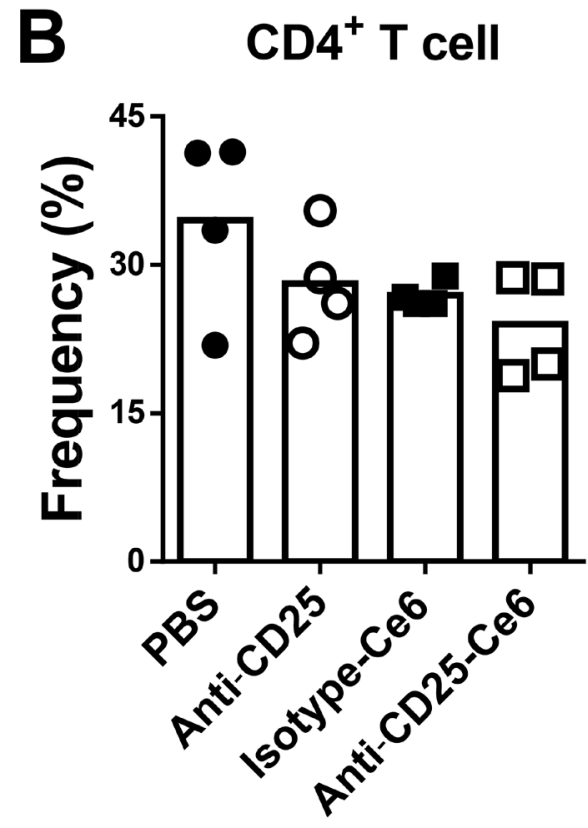

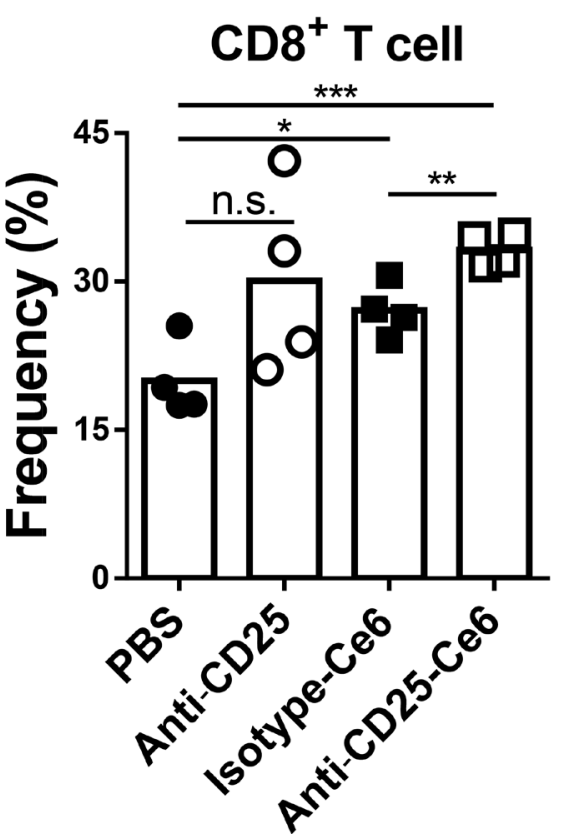

Figure 3: Anti-CD25-Ce6-targeted PDT induces CD8 ${ }^{+}$T-cell tumor infiltration. (A and B) Ten days after tumor inoculation, PBS, anti-CD25 antibody, isotype-Ce6, or anti-CD25-Ce6 was injected intratumorally, after which PDT was performed twice at a 2-day interval. (A) Tumor-infiltrated T cells were examined using flow cytometry. (B) Results shown as bar graphs. ( $n=4$ mice per group; Student's $t$ test, $* P<0.05,{ }^{*} P<<0.01,{ }^{* * *} P<0.001$; error bars represent SEM). Data are representative of three independent experiments. 
dependent cellular phagocytosis, we observed that Treg depletion was limited to the tumor site and that anti-CD25Ce6-targeted PDT did not alter the Treg population of the draining lymph node or the systemic immune response to influenza infection. Part of the success may be attributed to the low dose of anti-CD25-Ce6 injected intratumorally, which is only $1 / 20$ to $1 / 40$ of the concentration used in conventional Treg-targeted immunotherapy [35]. Treg depletion by anti-CD25-Ce6-targeted PDT induced significant inhibition in B16-F10 melanoma growth, whereas administration of unconjugated anti-CD25 antibody or isotype-Ce6 did not affect tumor growth.

Our study confirmed that CD25-Ce6-targeted PDT inhibited growth of B16-F10 tumors and increased antitumor immunity at the tumor site. Further studies are required to determine if the adaptive immune response generated following CD25-Ce6-targeted PDT could inhibit tumors growing at other sites. Notably, the average tumor size was $128.6 \pm 17 \mathrm{~mm}^{3}$ at treatment initiation. We think our therapy is less effective for large tumors because the laser cannot penetrate deep inside the mass. To improve therapy efficiency, we could use a laser with longer wavelength for deeper penetration into tumor tissue. In that case, $\mathrm{Ce} 6$ should be replaced by another molecule that can be excited at longer wavelength. Future studies will focus on optimizing the amount of anti-CD25Ce6 injected and the administration route to minimize systemic side effects and maximize localized and specific Treg depletion using PDT.

Off-target PDT can induce tissue damage or abnormality [12]. Here, we showed that anti-CD25-Ce6 could specifically deplete Treg in tumor tissue after PDT,
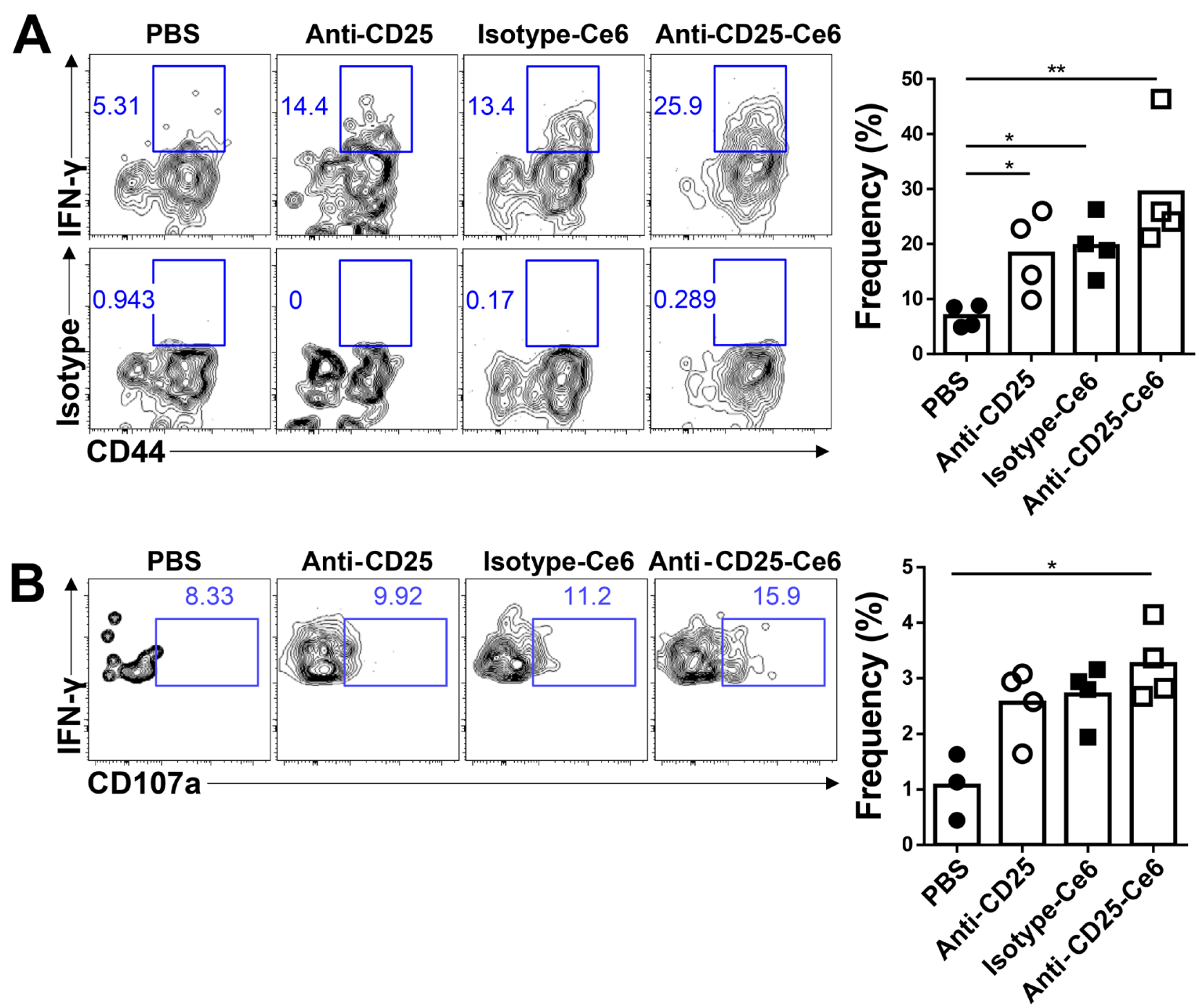

Figure 4: Anti-CD25-Ce6-targeted PDT induces cytotoxic T-cell responses and T-cell polyfunctionality. (A and B) Ten days after B16-F10-cell inoculation, PBS, anti-CD25 antibody, isotype-Ce6, or anti-CD25-Ce6 was injected intratumorally and PDT was performed twice at a 2-day interval. (A) IFN- $\gamma^{+}$- or (B) IFN- $\gamma^{+} \mathrm{CD} 107 \mathrm{a}^{+}$-expressing activated tumor-infiltrated CD8 ${ }^{+} \mathrm{T}$-cell populations were assessed by intracellular cytokine staining following stimulation with phorbol myristate acetate/ionomycin. ( $n=4$ mice per group; Student's $t$ test, $* P<0.05, * * P<0.01)$. Data are representative of three independent experiments. 
thus minimizing unwanted tissue damage. Considering that other cell populations in the tumor tissue were not affected by irradiation, it is very unlikely that our therapy would cause systemic side effects. Furthermore, we also assessed whether the systemic immune system was influenced by locally administered anti-CD25 antibody because systemic depletion of Treg cells could alter systemic immunity and cause severe side effects. However, as shown in Figure 5 and Supplementary Figure 2, we observed that the adaptive immune response to influenza infection was not affected after our therapy. These results show that local administration of anti-CD25-Ce6 can specifically deplete target cells without affecting other cell populations or causing systemic side effects.

Treg depletion induces tumor rejection by enhancing infiltration and activation of $\mathrm{CD}^{+} \mathrm{T}$ cells in tumors $[7,28]$. Tregs reduce $\mathrm{CD} 8^{+} \mathrm{T}$-cell expansion and effector differentiation, resulting in reduced production of effector cytokines and cytotoxicity through various mechanisms [36]. In particular, it is known that Treg decreases $\mathrm{T}$ cell
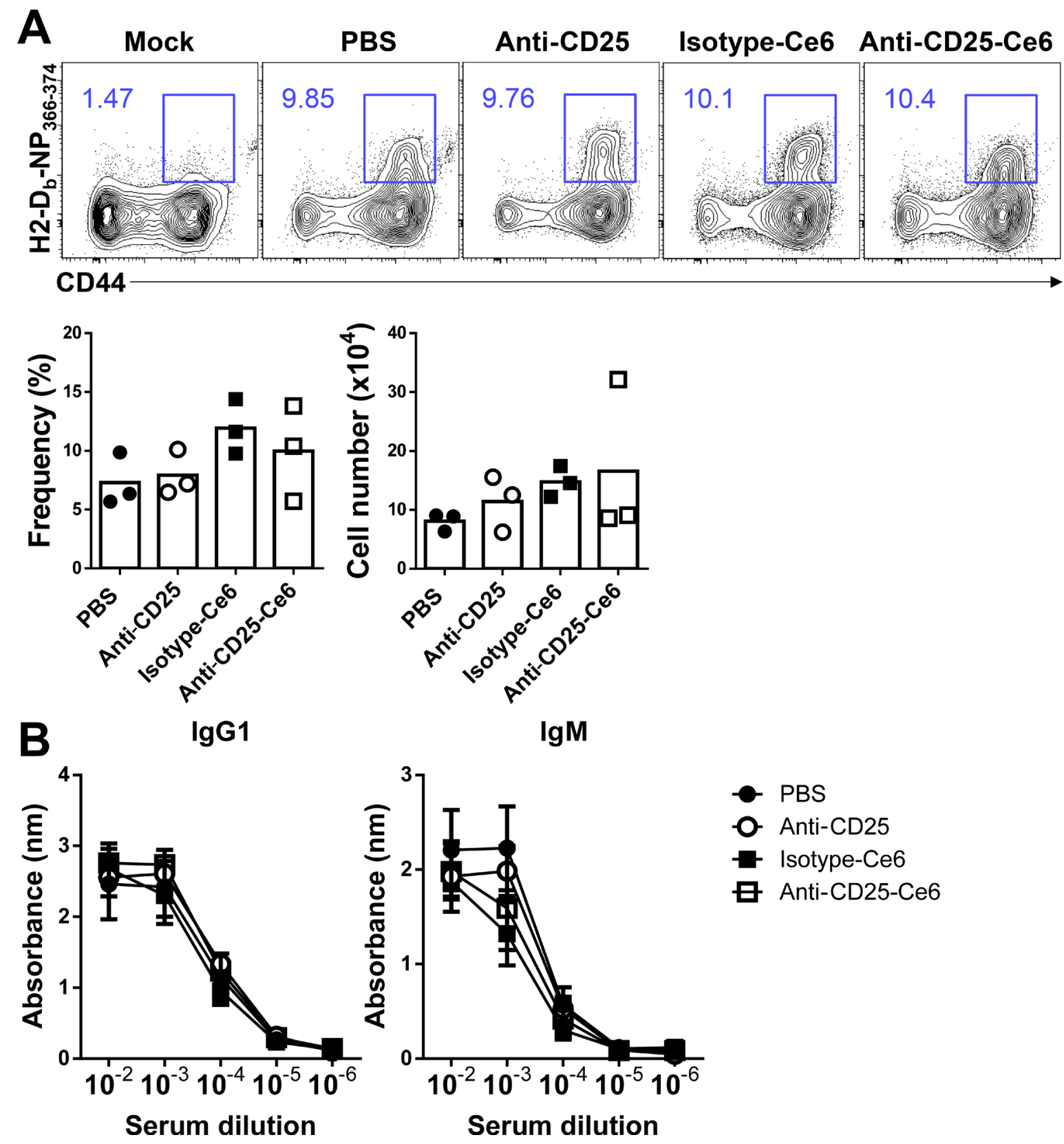

Figure 5: Anti-CD25-Ce6-targeted PDT does not affect the adaptive immune response against influenza infection. (A) Mice were intranasally administered PR8 5 days after B16-F10 inoculation. Six days after PR8 infection, PDT was performed twice at a 2-day interval. PR8 $\mathrm{NP}_{366-374}$-specific $\mathrm{CD}^{+} \mathrm{T}$ cells in lungs were monitored using flow cytometry with the $\mathrm{H}_{2}-\mathrm{Db}-\mathrm{NP}{ }_{366-374}$ pentamer. (B) Bar graph of the frequency of PR8 $\mathrm{NP}_{366-374}$-specific CD8 ${ }^{+} \mathrm{T}$ cells. ( $n=3$ mice per group; Student's $t$ test; error bars represent SEM). Data are representative of two independent experiments. 

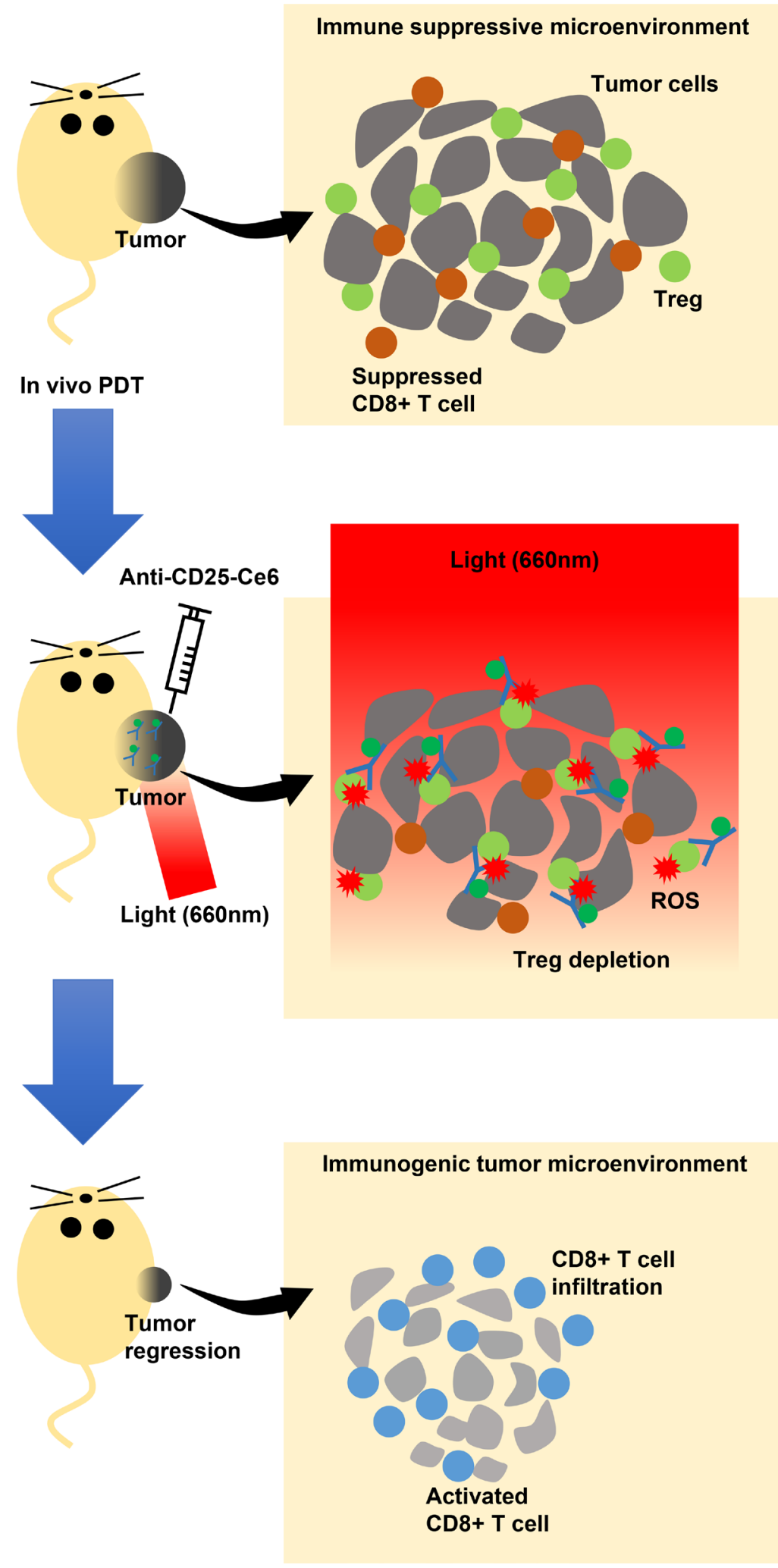

Figure 6: Scheme of the proposed mechanism of intratumoral Tregs-targeted photodynamic immunotherapy to induce anti-tumoral immune responses in a mouse melanoma model. Tregs (green circle) suppress $\mathrm{CD} 8^{+} \mathrm{T}$ cell (brown circle) activation infiltrated within the tumor microenvironment, which is permissive for growth (upper panel). Mice are injected intratumorally with anti-CD25-Ce6. PDT with a 660-nm laser is applied to the injection site so that Tregs in the tumor site are specifically depleted by the ROS generated by anti-CD25-Ce6, thus modulating the local immune environment (middle panel). Activated $\mathrm{CD}^{+} \mathrm{T}$ cells (blue circle) infiltrated into the tumor microenvironment can attack tumors, inhibiting their growth (lower panel). 
polyfunctionality [37]. CD107a (lysosomal-associated membrane protein 1, LAMP1) is one of the major markers of polyfunctional $\mathrm{T}$ cells that is expressed on the surface of cells undergoing degranulation. CD107a also serves as a marker of cytotoxicity, and CD107a $+\mathrm{CD} 8+\mathrm{T}$ cells exhibit anti-tumor activity in an antigen-specific manner [37]. Therefore, $\mathrm{CD} 8+\mathrm{T}$ cell polyfunctionality is very closely associated with the anti-tumor effect in vivo [38].

Our findings are consistent with previous studies that used a genetically engineered Treg depletion mouse model and an antibody-targeted therapy model. These studies showed that immune-suppressive tumor microenvironments can be altered. Similarly, anti-CD25Ce6-targeted PDT altered the immune-suppressive tumor microenvironment via Treg depletion that induced IFN- $\gamma$ production in $\mathrm{CD} 8^{+} \mathrm{T}$ cells and increased $\mathrm{CD} 8^{+} \mathrm{T}$-cell polyfunctionality, which is also in accordance with previous findings $[27,30]$.

Furthermore, Tregs maintain immune homeostasis by limiting T-cell responses to self, environmental, and pathogen-associated antigens and by modulating immune responsiveness [33]. Because systemic Treg depletion can induce hyper-immune responses and autoimmune responses, a local and specific Treg depletion strategy is required for cancer immunotherapy. Our anti-CD25-Ce6targeted PDT did not affect systemic immune responses to pathogens, as shown by unaltered immune responses against influenza infection. Thus, we demonstrated that antibody-targeted PDT can be used for targeting specific cell populations within tissues without inducing severe systemic side effects.

Here, we used $\mathrm{Ce} 6$ conjugated to an anti-CD25 monoclonal antibody for phototherapeutic depletion of tumor-associated Tregs. However, other markers for targeting tumor-infiltrated Tregs, such as OX40 and CTLA-4, are also available [39]. Thus, further studies will examine the use of these surface molecules as targets for antibody-targeted PDT for the depletion of Tregs. Furthermore, it is important to understand the functions of immune cells other than Tregs within tumor microenvironments to develop effective immune therapies. Although our study focused on Tregs, other immune cells, such as myeloid-derived suppressor cells and tumorassociated macrophages, play immune-suppressive roles within tumor tissues [40]. Thus, future studies will apply antibody-targeted PDT to similarly study the roles of these cells.

In conclusion, we showed that PDT targeting $\mathrm{CD} 25^{+} \mathrm{Foxp}^{+}$tumor-infiltrated Tregs could achieve selective depletion of Tregs within the tumor microenvironment without inducing systemic side effects in a mouse melanoma model. After Treg depletion, CD8 ${ }^{+}$ T-cell infiltration and activation increased within tumor tissues, and tumor growth was inhibited (Figure 6). Thus, we demonstrated that anti-CD25-Ce6-targeted PDT could specifically modulate the tumor microenvironment by depleting Tregs, making it a novel option for tumor immunotherapy.

\section{MATERIALS AND METHODS}

\section{Mice}

C57BL/6-Tg (Foxp3-GFP) 90Pkraj/J mice were purchased from Jackson Laboratory. Specific pathogenfree (SPF)-conditioned 8- to 12-week-old C57BL/6 male mice were purchased from DBL Co. Ltd Korea. All mice were bred in a SPF facility and animal care and housing occurred in the SPF facility of the Korea Advanced Institute of Science and Technology (KAIST). All animal procedures were in agreement with the guidelines and protocols (KA2016-19) for rodent research provided by the Institutional Animal Care and Use Committee of KAIST.

\section{Synthesis of the anti-CD25-Ce6 conjugate}

For the conjugation of Ce6 (Santa Cruz Biotechnology) to anti-mouse CD25 antibody (Clone PC61, BioLegend) and rat $\operatorname{IgG1\lambda }$ isotype antibody (BioLegend), the carboxylic groups of $\mathrm{Ce} 6$ were activated by reacting Ce6 dissolved in anhydrous DMSO $(5 \mathrm{mg} / \mathrm{ml}$; Sigma-Aldrich) with equimolar N-hydroxysuccinimide (Sigma-Aldrich) and 1-ethyl-3-(3-dimethylaminopropyl) carbodiimide (Sigma-Aldrich) dissolved in DMSO $(5 \mathrm{mg} / \mathrm{ml})$ for $1 \mathrm{~h}$ at room temperature. The DMSO solution was then mixed with antibody solution $(0.5 \mathrm{mg} /$ $\mathrm{ml}$ ) for $2 \mathrm{~h}$ at room temperature. The ratio between $\mathrm{Ce} 6$ and antibody was 100 to 1 . The unbound $\mathrm{Ce} 6$ molecules were removed using PD-10 desalting columns (GE Healthcare). The number of $\mathrm{Ce} 6$ conjugated to each antibody molecule was estimated by measuring the absorbance of Ce6; approximately $10 \mathrm{Ce} 6$ molecules were conjugated to each antibody molecule. The fluorescence spectra of anti-CD25 and anti-CD25-Ce6 were measured using Gemini XPS spectrofluorometer (Molecular Devices).

\section{Protein gel electrophoresis}

To determine the anti-CD25-Ce6 conjugate molecular weights, $3 \mu \mathrm{g}$ anti-CD25 or anti-CD25-Ce6 mixed with SDS-PAGE loading buffer (LPS solution) was boiled at $100^{\circ} \mathrm{C}$ for $10 \mathrm{~min}$. Samples were run on SDS-PAGE (10\% gel) and developed with Coomassie blue dye solution. Molecular weights of each sample were determined with Xpert Prestained protein marker (GenDEPOT).

\section{Anti-CD25-Ce6 conjugate binding assay}

To see the binding of anti-CD25-Ce6 conjugates to $\mathrm{CD}^{+}{ }^{+}$Foxp $3^{+}$cells in vitro, $\mathrm{CD} 4^{+} \mathrm{T}$ cells were enriched 
from Foxp3-GFP mouse spleens using a MagniSort Mouse CD4 T-cell Enrichment Kit (eBioscience). Foxp3 ${ }^{+}$cells were then sorted with a FACSAria II (BD Biosciences). These cells were stained with $5 \mu \mathrm{g}$ anti-CD25-Ce6 or isotype-Ce6 on ice for $25 \mathrm{~min}$. Next, these cells were washed and stained with Goat APC conjugated-antimouse IgG (Jackson Immuno Research). Anti-CD25-Ce6 conjugate binding was monitored with a FACSCalibur (BD Biosciences).

To measure the binding of anti-CD25-Ce6 conjugate to $\mathrm{CD}^{+}{ }^{+}$Foxp $^{+}$cells in vivo, B16-F10 mouse melanoma cells were subcutaneously transplanted into Foxp3GFP mice. Anti-CD25-Ce6 or isotype-Ce6 was injected intratumorally 12 days after B16-F10 transplantation, and tumor masses were dissected $30 \mathrm{~min}$ after injection. Tumor masses were minced with a razor blade and digested with a mixture of $2 \mathrm{mg} / \mathrm{ml}$ Collagenase IV (Worthington Biochemical Corp) and $30 \mu \mathrm{g} / \mathrm{ml}$ DNase I (Roche) in PBS for $30 \mathrm{~min}$ at $37^{\circ} \mathrm{C}$. The digested tumors were passed through 70- $\mu \mathrm{m}$ cell strainers (SPL). After cell suspensions were washed with PBS, red blood cells were depleted with ACK lysis buffer. Next, cell suspensions were washed and stained with Goat APC conjugated-anti-mouse IgG (Jackson Immuno Research). Anti-CD25-Ce6 conjugate binding was monitored with a FACSCalibur.

\section{In vitro apoptosis assay}

$\mathrm{CD}^{+} \mathrm{T}$ cells were enriched from Foxp3-GFP mouse spleens using a MagniSort Mouse CD4 T-cell Enrichment Kit (eBioscience). Foxp3 $3^{+}$cells were then sorted for using a FACSAria II (BD Biosciences). Sorted cells were stained with $5 \mu \mathrm{g}$ of anti-CD25-Ce6 or isotype-Ce6 on ice for $25 \mathrm{~min}$. Stained cells were washed and $5 \times 10^{4}$ cells were plated in each well of 96-well flat-bottom plates (FALCON) in RPMI-1640 media (Welgene) with 10\% fetal bovine serum (Welgene). Plates were centrifuged for $5 \mathrm{~min}$ at $1500 \mathrm{rpm}$. Cells in each well were irradiated with a $660-\mathrm{nm}$ laser $\left(100 \mathrm{~mW} / \mathrm{cm}^{2}\right)$ (Micro Laser Systems) for 5 min. Cell apoptosis after $30 \mathrm{~min}$ or $15 \mathrm{~h}$ of incubation was measured by detecting surface annexin V (BioLegend) expression by a FACSCalibur (BD Biosciences).

\section{In vivo PDT}

B16-F10 mouse melanoma cells were cultured in Dulbecco's Modified Eagle Medium (Welgene) containing 10\% fetal bovine serum (Welgene) and 1\% penicillin/streptomycin (Welgene). Once cells reached approximately 80-90\% confluency, cells were harvested using Trypsin/EDTA (Welgene) and rinsed with PBS (GenDEPOT). The flanks of mice were subcutaneously injected with $5 \times 10^{5}$ cells in $100 \mu \mathrm{l}$ PBS. Ten days after tumor inoculation, mice were randomized into four groups that were injected with $20 \mu$ of PBS $(n=6)$, anti-CD25Ce6 $(n=6)$, isotype-Ce6 $(n=5)$, or free anti-CD25 $(n=6)$ intratumorally four times total at 2-day intervals. The tumors were injected with anti-CD25-Ce6 or isotypeCe6 and irradiated $\left(660 \mathrm{~nm}\right.$, approximately $100 \mathrm{~mW} / \mathrm{cm}^{2}$, $30 \mathrm{~min}$ ) by laser $30 \mathrm{~min}$ after injection. Tumor volumes were measured at 3-day intervals for 24 days by a blinded investigator with calipers using the following equation: Tumor volume $=\left(\mathrm{L} \times \mathrm{W}^{2}\right) / 2$, where $\mathrm{L}$ indicates the length of the long side and $\mathrm{W}$ indicates that of the short side.

\section{Intracellular cytokine staining and flow cytometric analysis}

To determine the anti-tumor immune response following PDT, in vivo PDT was performed twice on two separate groups of mice. Mice were sacrificed using carbon dioxide gas from the last PDT treatment. Tumor masses were isolated, minced with a razor blade, and digested with a mixture of $2 \mathrm{mg} / \mathrm{ml}$ Collagenase IV (Worthington Biochemical Corp) and $30 \mu \mathrm{g} / \mathrm{ml}$ DNase I (Roche) in PBS for $30 \mathrm{~min}$ at $37^{\circ} \mathrm{C}$. The digested tumors were passed through $70-\mu \mathrm{m}$ cell strainers (SPL). After cell suspensions were washed with PBS, red blood cells were depleted by ACK lysis buffer. To monitor $\mathrm{CD}^{+}$ or $\mathrm{CD}^{+} \mathrm{T}$-cell infiltration, cells were stained with antimouse CD4 (Clone GK1.5, BioLegend), anti-mouse CD8 $\alpha$ (Clone 53-6.7, BioLegend), anti-mouse CD11b (Clone M1/70, BD Biosciences), anti-mouse CD45.2 (Clone 104, BioLegend), and anti-mouse CD3e (Clone 145-2C11, eBioscience). Dead cells were excluded using DAPI staining. All samples were acquired on an LSR II Cell Analyzer (BD Biosciences).

Intracellular cytokine staining was performed using previously described methods [41, 42]. Briefly, cells were incubated with $50 \mathrm{ng} / \mathrm{mL}$ phorbol myristate acetate (Sigma-Aldrich), $1 \mu \mathrm{g} / \mathrm{mL}$ ionomycin (SigmaAldrich), $2 \mu \mathrm{M}$ GolgiStop (BD Biosciences), and $2 \mu \mathrm{M}$ GolgiPlug (BD Biosciences) for $5 \mathrm{~h}$ in a $37^{\circ} \mathrm{C}$ incubator. Cells were then stained with anti-mouse CD4, anti-mouse CD8 $\alpha$, anti-mouse CD11b, anti-mouse CD44 (Clone IM7, Tonbo Biosciences), and anti-mouse CD45.2, and then fixed and permeabilized using a Cytofix/Cytoperm Kit (BD Biosciences) according to the manufacturer's protocol. To detect intracellular cytokines, IFN- $\gamma$ antibody (Clone XMG1.2, BD Biosciences) and CD107a antibody (Clone1D4B, BD Biosciences) were used. All samples were acquired on an LSR II Cell Analyzer and data were analyzed using FlowJo software (Tree Star).

\section{PR8-specific pentamer staining}

To examine cytotoxic T-cell responses against lung PR8 influenza infection following in vivo PDT, tumorbearing mice were intranasally infected with PR8 virus (25 PFU/mouse) 5 days after B16-F10 inoculation. Mice were treated with anti-CD25-Ce6-targeted PDT 6 days after infection with PR8. Then PDT was carried out 6 days 
after PR8 infection as described above. After two PDT treatments given at a 2-day interval, mice were sacrificed with carbon dioxide gas, and the lungs were isolated. Lungs were minced with a razor blade and digested with a mixture of $2 \mathrm{mg} / \mathrm{ml}$ collagenase IV and $30 \mu \mathrm{g} / \mathrm{ml}$ DNase I in Dulbecco's Modified Eagle Medium for $30 \mathrm{~min}$ at $37^{\circ} \mathrm{C}$. The digested lung tissue was passed through $70-\mu \mathrm{m}$ cell strainers. The cell suspensions were washed with PBS, and red blood cells were depleted with ACK lysis buffer. Cells were stained with anti-mouse CD8 $\alpha$, anti-mouse CD11b, anti-mouse CD45.2, anti-mouse CD44, and PR8 $\mathrm{NP}_{366-374}$ pentamer (ProImmune). All samples were acquired on an LSR Fortessa Cell Analyzer (BD Biosciences), and data were analyzed using FlowJo software.

\section{Serum antibody titration}

To examine humoral immune responses to PR8 infection after in vivo anti-CD25-Ce6-targeted PDT, tumor-bearing mice were infected with PR8 (10 PFU) and subjected to anti-CD25-Ce6-targeted PDT as described above. Mice were sacrificed 14 days after PR8 infection with carbon dioxide gas. To obtain mouse serum, blood was collected via heart puncture and allowed to clot at $37^{\circ} \mathrm{C}$ for $1 \mathrm{~h}$. The serum was prepared by centrifugation for $10 \mathrm{~min}$ at $10000 \mathrm{rpm}$ and stored in $-80^{\circ} \mathrm{C}$. To determine the amount of PR8-specific IgG1 and IgM in serum, MaxiSorp 96-well plates (Nunc) were coated with formalin-fixed PR8, and diluted sera were added to detect the serum levels of PR8-specific IgG1 and IgM antibodies. The presence of PR8 antibodies was detected with horseradish peroxidaseconjugated goat anti-mouse IgG1 (Jackson Laboratory) or horseradish peroxidase-conjugated goat anti-mouse IgM (Life Technologies) antibodies. Color was developed in the plates with 3,3,5,5'-Tetramethylbenzidine (eBioscience) and stopped with $\mathrm{H}_{2} \mathrm{SO}_{4}$ buffer. Absorbance at $450 \mathrm{~nm}$ was measured with an iMark ${ }^{\mathrm{TM}}$ Microplate Absorbance Reader (Bio-Rad).

\section{Statistical analysis}

Data are expressed as the means \pm standard error of the mean (SEM). Differences among groups were analyzed using unpaired, two-tailed Student's $t$ tests. Tumor growth was analyzed using two-way ANOVA tests. Statistical analysis was performed using GraphPad Prism software (GraphPad). Differences were considered statistically significant when $P<0.05$, and are indicated as: $* P<0.05,{ }^{* *} P<0.01$, and $* * * P<0.001$.

\section{Abbreviations}

Ce6: Chlorin e6; DMSO: dimethyl sulfoxide ; PDT: photodynamic therapy; ROS: reactive oxygen species; SEM: standard error of the mean; SPF: specific pathogenfree ; Tregs: regulatory $\mathrm{T}$ cells.

\section{Authors' contributions}

D.S.O., H.G.K., J.H.P., and H.K.L. designed the study. D.S.O., H.G.K., J.E.O., H.E.J. and Y.S.L. performed the research. D.S.O., H.G.K., J.H.P., and H.K.L. conceived the study, analyzed the data, and wrote the manuscript.

\section{ACKNOWLEDGMENTS}

The authors would like to thank the members of the Laboratory of Host Defenses and the members of Immune Engineering Seminar for helpful advice on experiments and data discussions.

\section{CONFLICTS OF INTEREST}

The authors have no conflicting financial interests.

\section{FUNDING}

H.K.L. was supported by the National Research Foundation (NRF-2016R1A2B2015028, NRF2015R1A4A1042416, NRF-2014M3A9A5044964, NRF-2012M3A9B4028274) and KAIST Future Systems Healthcare Project funded by the Ministry of Science, ICT, and Future Planning of Korea. J.-H.P. was supported by the Basic Science Research Program (NRF2015R1A1A1A05001420) through the National Research Foundation funded by the Ministry of Science, ICT \& Future Planning, Republic of Korea. H.K.L. and J.-H.P. were supported by KAIST KI Convergence Project for Health Science and Technology.

\section{REFERENCES}

1. Chen DS, Mellman I. Oncology meets immunology: the cancer-immunity cycle. Immunity. 2013; 39:1-10. doi: 10.1016/j.immuni.2013.07.012.

2. Childs RW, Carlsten M. Therapeutic approaches to enhance natural killer cell cytotoxicity against cancer: the force awakens. Nat Rev Drug Discov. 2015; 14:487-98. doi: $10.1038 /$ nrd4506.

3. Rosenberg SA. Cancer immunotherapy comes of age. Nat Clin Pract Oncol. 2005; 2: 115. doi: 10.1038/ncponc0101.

4. Sharma P, Allison JP. The future of immune checkpoint therapy. Science. 2015; 348:56-61. doi: 10.1126/science. aaa8172.

5. Lindau D, Gielen P, Kroesen M, Wesseling P, Adema GJ. The immunosuppressive tumour network: myeloid-derived suppressor cells, regulatory T cells and natural killer T cells. Immunology. 2013; 138:105-15. doi: 10.1111/imm.12036.

6. Nishikawa H, Sakaguchi S. Regulatory T cells in cancer immunotherapy. Current Opinion in Immunology. 2014; 27:1-7. doi: 10.1016/j.coi.2013.12.005. 
7. Chen ML, Pittet MJ, Gorelik L, Flavell RA, Weissleder R, von Boehmer H, Khazaie K. Regulatory T cells suppress tumor-specific CD8 $\mathrm{T}$ cell cytotoxicity through TGFbeta signals in vivo. Proc Natl Acad Sci U S A. 2005; 102:419-24. doi: 10.1073/pnas.0408197102.

8. Colombo MP, Piconese S. Regulatory-T-cell inhibition versus depletion: the right choice in cancer immunotherapy. Nat Rev Cancer. 2007; 7:880-7. doi: 10.1038/nrc2250.

9. Bluestone JA. Regulatory T-cell therapy: is it ready for the clinic? Nature Reviews Immunology. 2005; 5:343-9. doi: 10.1038/nri1574.

10. Wing K, Sakaguchi S. Regulatory T cells exert checks and balances on self tolerance and autoimmunity. Nature Immunology. 2010; 11:7-13. doi: 10.1038/ni.1818.

11. Sakaguchi S, Ono M, Setoguchi R, Yagi H, Hori S, Fehervari Z, Shimizu J, Takahashi T, Nomura T. Foxp3+ $\mathrm{CD} 25+\mathrm{CD} 4+$ natural regulatory $\mathrm{T}$ cells in dominant selftolerance and autoimmune disease. Immunol Rev. 2006; 212:8-27. doi: 10.1111/j.0105-2896.2006.00427.x.

12. Huang $Z$. A review of progress in clinical photodynamic therapy. Technol Cancer Res Treat. 2005; 4:283-93. doi: 10.1177/153303460500400308.

13. Bonnett R. Photosensitizers of the Porphyrin and Phthalocyanine Series for Photodynamic Therapy. Chemical Society Reviews. 1995; 24:19-33. doi: 10.1039/ cs9952400019.

14. Castano AP, Mroz P, Hamblin MR. Photodynamic therapy and anti-tumour immunity. Nature Reviews Cancer. 2006; 6:535-45. doi: 10.1038/nrc1894.

15. Gollnick SO, Brackett CM. Enhancement of anti-tumor immunity by photodynamic therapy. Immunologic Research. 2010; 46:216-26. doi: 10.1007/s12026-009-8119-4.

16. Mitsunaga M, Ogawa M, Kosaka N, Rosenblum LT, Choyke PL, Kobayashi H. Cancer cell-selective in vivo near infrared photoimmunotherapy targeting specific membrane molecules. Nature Medicine. 2011; 17:1685-U210. doi: 10.1038/nm.2554.

17. Mew D, Lum V, Wat CK, Towers GH, Sun CH, Walter RJ, Wright W, Berns MW, Levy JG. Ability of Specific Monoclonal-Antibodies and Conventional Antisera Conjugated to Hematoporphyrin to Label and Kill Selected Cell-Lines Subsequent to Light Activation. Cancer Research. 1985; 45:4380-6.

18. Sato K, Sato N, Xu BY, Nakamura Y, Nagaya T, Choyke PL, Hasegawa Y, Kobayashi H. Spatially selective depletion of tumor-associated regulatory $\mathrm{T}$ cells with near-infrared photoimmunotherapy. Science Translational Medicine. 2016; 8:352ra110. doi: 10.1126/scitranslmed.aaf6843.

19. Chen X, Du Y, Huang Z. CD4+CD25+ Treg derived from hepatocellular carcinoma mice inhibits tumor immunity. Immunol Lett. 2012; 148:83-9. doi: 10.1016/j. imlet.2012.09.002.

20. Khazaie K, von Boehmer H. The impact of CD4+CD25+ Treg on tumor specific CD8+ T cell cytotoxicity and cancer.
Semin Cancer Biol. 2006; 16:124-36. doi: 10.1016/j. semcancer.2005.11.006.

21. Diao Z, Shi J, Zhu J, Yuan H, Ru Q, Liu S, Liu Y, Zheng D. TRAIL suppresses tumor growth in mice by inducing tumor-infiltrating CD4(+)CD25 (+) Treg apoptosis. Cancer Immunol Immunother. 2013; 62:653-63. doi: 10.1007/ s00262-012-1370-x.

22. Onizuka S, Tawara I, Shimizu J, Sakaguchi S, Fujita T, Nakayama E. Tumor rejection by in vivo administration of anti-CD25 (interleukin-2 receptor alpha) monoclonal antibody. Cancer Res. 1999; 59:3128-33.

23. Huang P, Lin J, Wang SJ, Zhou ZJ, Li ZM, Wang Z, Zhang CL, Yue XY, Niu G, Yang M, Cui DX, Chen XY. Photosensitizerconjugated silica-coated gold nanoclusters for fluorescence imaging-guided photodynamic therapy. Biomaterials. 2013; 34:4643-54. doi: 10.1016/j.biomaterials.2013.02.063.

24. Huang P, Xu C, Lin J, Wang C, Wang X, Zhang C, Zhou X, Guo S, Cui D. Folic Acid-conjugated Graphene Oxide loaded with Photosensitizers for Targeting Photodynamic Therapy. Theranostics. 2011; 1:240-50.

25. Miyara M, Yoshioka Y, Kitoh A, Shima T, Wing K, Niwa A, Parizot C, Taflin C, Heike T, Valeyre D, Mathian A, Nakahata T, Yamaguchi T, et al. Functional delineation and differentiation dynamics of human CD4+ T cells expressing the FoxP3 transcription factor. Immunity. 2009; 30:899-911. doi: 10.1016/j.immuni.2009.03.019.

26. Siddiqui SA, Frigola X, Bonne-Annee S, Mercader M, Kuntz SM, Krambeck AE, Sengupta S, Dong H, Cheville JC, Lohse CM, Krco CJ, Webster WS, Leibovich BC, et al. Tumor-infiltrating Foxp3-CD4+CD25+ T cells predict poor survival in renal cell carcinoma. Clin Cancer Res. 2007; 13:2075-81. doi: 10.1158/1078-0432.CCR-06-2139.

27. Li X, Kostareli E, Suffner J, Garbi N, Hammerling GJ. Efficient Treg depletion induces T-cell infiltration and rejection of large tumors. Eur J Immunol. 2010; 40:3325-35. doi: 10.1002/eji.201041093.

28. McNally A, Hill GR, Sparwasser T, Thomas R, Steptoe RJ. $\mathrm{CD} 4+\mathrm{CD} 25+$ regulatory $\mathrm{T}$ cells control $\mathrm{CD} 8+\mathrm{T}$-cell effector differentiation by modulating IL-2 homeostasis. Proc Natl Acad Sci USA. 2011; 108:7529-34. doi: 10.1073/ pnas. 1103782108.

29. Yuan J, Gnjatic S, Li H, Powel S, Gallardo HF, Ritter E, Ku GY, Jungbluth AA, Segal NH, Rasalan TS, Manukian G, $\mathrm{Xu}$ Y, Roman RA, et al. CTLA-4 blockade enhances polyfunctional NY-ESO-1 specific $\mathrm{T}$ cell responses in metastatic melanoma patients with clinical benefit. Proc Natl Acad Sci U S A. 2008; 105:20410-5. doi: 10.1073/ pnas.0810114105.

30. Ellis JS, Wan X, Braley-Mullen H. Transient depletion of CD4+ $\mathrm{CD} 25+$ regulatory $\mathrm{T}$ cells results in multiple autoimmune diseases in wild-type and B-cell-deficient NOD mice. Immunology. 2013; 139:179-86. doi: 10.1111/imm.12065.

31. Sakaki M, Hiroishi K, Baba T, Ito T, Hirayama Y, Saito K, Tonoike T, Kushima M, Imawari M. Intrahepatic status 
of regulatory $\mathrm{T}$ cells in autoimmune liver diseases and chronic viral hepatitis. Hepatol Res. 2008; 38:354-61. doi: 10.1111/j.1872-034X.2007.00284.x.

32. Weiner LM. Cancer immunotherapy--the endgame begins. N Engl J Med. 2008; 358:2664-5. doi: 10.1056/ NEJMp0803663.

33. Liston A, Gray DH. Homeostatic control of regulatory $\mathrm{T}$ cell diversity. Nat Rev Immunol. 2014; 14:154-65. doi: 10.1038/nri3605.

34. Rech AJ, Mick R, Martin S, Recio A, Aqui NA, Powell DJ, Colligon TA, Trosko JA, Leinbach LI, Pletcher $\mathrm{CH}$, Tweed CK, DeMichele A, Fox KR, et al. CD25 Blockade Depletes and Selectively Reprograms Regulatory T Cells in Concert with Immunotherapy in Cancer Patients. Science Translational Medicine. 2012; 4:134ra62. doi: 10.1126/ scitranslmed.3003330.

35. Simpson TR, Li FB, Montalvo-Ortiz W, Sepulveda MA, Bergerhoff K, Arce F, Roddie C, Henry JY, Yagita H, Wolchok JD, Peggs KS, Ravetch JV, Allison JP, et al. Fcdependent depletion of tumor-infiltrating regulatory $\mathrm{T}$ cells co-defines the efficacy of anti-CTLA-4 therapy against melanoma. Journal of Experimental Medicine. 2013; 210:1695-710. doi: 10.1084/jem.20130579.

36. Corthay A. How do Regulatory T Cells Work? Scandinavian Journal of Immunology. 2009; 70:326-36. doi: 10.1111/j.1365-3083.2009.02308.x.
37. Seder RA, Darrah PA, Roederer M. T-cell quality in memory and protection: implications for vaccine design. Nat Rev Immunol. 2008; 8:247-58. doi: 10.1038/nri2274.

38. Appay V, Douek DC, Price DA. CD8+ T cell efficacy in vaccination and disease. Nat Med. 2008; 14:623-8. doi: 10.1038/nm.f.1774.

39. Marabelle A, Kohrt H, Sagiv-Barfi I, Ajami B, Axtell RC, Zhou G, Rajapaksa R, Green MR, Torchia J, Brody J, Luong R, Rosenblum MD, Steinman L, et al. Depleting tumor-specific Tregs at a single site eradicates disseminated tumors. Journal of Clinical Investigation. 2013; 123:244763. doi: 10.1172/Jci64859.

40. Smyth MJ, Ngiow SF, Ribas A, Teng MW. Combination cancer immunotherapies tailored to the tumour microenvironment. Nat Rev Clin Oncol. 2016; 13:143-58. doi: 10.1038/nrclinonc.2015.209.

41. Oh JE, Kim BC, Chang DH, Kwon M, Lee SY, Kang D, Kim JY, Hwang I, Yu JW, Nakae S, Lee HK. Dysbiosisinduced IL-33 contributes to impaired antiviral immunity in the genital mucosa. Proc Natl Acad Sci U S A. 2016; 113: E762-71. doi: 10.1073/pnas.1518589113.

42. Shim YR, Lee HK. Caspase-1 independent viral clearance and adaptive immunity against mucosal respiratory syncytial virus infection. Immune Netw. 2015; 15:73-82. doi: 10.4110/in.2015.15.2.73. 